DOI https://doi.org/10.30525/978-9934-588-81-5-1.28

\title{
РЕЗУЛЬТАТЫ ИЗУЧЕНИЯ СУТОЧНОГО РАЦИОНА ПИТАНИЯ БОЛЬНЫХ АРТЕРИАЛЬНОЙ ГИПЕРТЕНЗИЕЙ С АБДОМИНАЛЬНЫМ ОЖИРЕНИЕМ
}

\author{
Коваль С. Н. \\ доктор медицинских наук, профессор, \\ заведуюший отделом артериальной гипертензии \\ и профилактики её осложнений \\ ГУ «Национальный институт терапии имени Л. Т. Малой \\ Национальной академии медицинских наук Украиныл»
}

Резник Л. А.

кандидат медииинских наук,

стариий научный сотрудник отдела артериальной гипертензии и профилактики её осложнений

ГУ «Национальный институт терапии имени Л. Т. Малой

Национальной академии медицинских наук Украины»

Старченко Т. Г.

кандидат медицинских наук,

старший научный сотрудник отдела артериальной гипертензии

и профилактики её осложнений

ГУ «Национальный институт терапии имени Л. Т. Малой

Национальной академии медицинских наук Украины»»

Пенькова М. Ю.

кандидат медицинских наук,

научный сотрудник отдела артериальной гипертензии и профилактики её осложнений

ГУ «Национальный институт терапии имени Л. Т. Малой

Нацииональной академии медиџинских наук Украины»»

$$
\text { 2. Харьков, Украина }
$$

Артериальная гипертензия (АГ) вносит значительный вклад в сердечно-сосудистую смертность населения во всем мире. Достаточно часто АГ ассоциируется с метаболическими нарушениями и, прежде всего, с абдоминальным ожирением (АО). АО одновременно является и алиментарно зависимым заболеванием, и фактором сердечнососудистого риска $[1$, с. 55]. При этом энергетическая ценность рациона питания является одним из важных факторов развития АО и тесно 
связана с макронутритивным статусом [2, с. 108]. В настоящее время исследуется роль отдельных нутриентов, пищевых продуктов и моделей питания в снижении кардиоваскулярного риска и в аспекте профилактики сердечно-сосудистых заболеваний [3, с. 52; 4, с. 2349]. Однако, данные о роли некоторых макронутриентов в генезе ожирения противоречивы и требуют дальнейших исследований. В связи с этим, целью исследования явилось изучение особенностей суточного рациона и режима питания больных АГ с АО.

Материалы и методы исследования.

Обследовано 95 больных (мужчин - 45, женщин - 50) АГ II стадии, 2-3 степени в возрасте от 38 до 63 лет. У 60 больных (мужчин 28 , женщин - 32) АГ протекала на фоне АО; 35 больных (мужчин 17 , женщин - 18) имели нормальную масса тела (НМТ). Больные АГ с AО и АГ с НМТ были сопоставимыми по возрасту и полу.

Всем больным проводили общеклиническое лабораторное и инструментальное обследование. Степень, стадию АГ оценивали в соответствии с рекомендациями Украинской ассоциации кардиологов (2013) [5, с. 11], Европейского общества гипертензии и Европейского общества кардиологов (2018 р.) [6, с. 3030]; выявление и оценку степени АО проводили по критериям ВО3 [7]. Энергетическую ценность пищи и суточное потребление белков, жиров и углеводов рассчитывали в соответствии с данными дневника суточного питания, с использованием специальных таблиц для подсчета калорийности и химического состава отдельных пищевых продуктов. Дневники пациенты заполняли в течение 4 суток. Нормальным считали соотношение белков, жиров и углеводов в суточном рационе, соответственно 1: 1: 4 [8].

Соответствие суточного рациона у обследованных пациентов нормам здорового питания оценивали согласно Европейским рекомендациям по профилактике сердечно-сосудистых заболеваний (2016): рекомендованный минимум пищевых волокон - 30 г в сутки; суточное потребление насыщенных жирных кислот не должно превышать 10\% от общей калорийности пищи, транс-ненасыщенных жирных кислот не более $1 \%$ от общей калорийности пищи [4].

Полученные данные были проанализированы с использованием компьютерной программы SPSS 19.0. для Windows XP. Данные исследования не отвечали критериям нормального распределения (критерием Шапиро - Уилки) и были представлены в виде медианы и интерквартильного интервала (Ме [25\%; 75\%]). Различия считались статистически значимыми при $\mathrm{p}<0,05$.

Результаты исследования и их обсуждение. Анализ данных анкетирования свидетельствует о наличии существенных различий в ха- 
рактере питания больных АГ с АО по сравнению с больными АГ с НМТ. Так, обнаружена достоверно более высокая $(\mathrm{p}<0,01)$ энергетическая ценность суточного рациона у больных АГ с АО - $(3101,4$ [2416,2; 3615,6] ккал), по сравнению с больными АГ с НМТ - $(2251,2$ [1988,4; 2584,2] ккал).

При анализе макронутриентного состава суточного рациона больных обеих групп было выявлено достоверное повышение суточного потребления жиров $(161,8$ [98,6; 184,2] г) и углеводов $(346,9$ [312,2; $372,8]$ г) в группе больных АГ с АО по сравнению с таковым у больных АГ с НМТ $(105,2$ [78,6; 136,8] г $(\mathrm{p}<0,05)$ и 266,0 [240,2; 351,2] г $(\mathrm{p}<0,05)$, соответственно).

На фоне повышенного потребления углеводов при АГ с АO по сравнению с больными АГ с НМТ отмечено также достоверное большее потребление в первой группе моносахаридов $(198,4$ [157,2; 221,7] $\Gamma, \mathrm{p}<0,05)$, чем в группе сравнения $(127,3[101,2 ; 178,4])$ г.

Суточное потребление белков в группе больных АГ как с АO, так и с НМТ достоверно не отличалось ( $>0,05)$.

В обеих группах пациентов отмечалось недостаточное потребление пищевых волокон при отсутствии достоверной разницы между больными АГ с АО и с НМТ. Потребление насыщенных жирных кислот и транс-ненасыщенных жирных кислот было достоверно больше в группе больных АГ с АО, чем в группе больных АГ с НМТ. Потребление насыщенных жирных кислот составляло в основной группе $15 \%$ суточной калорийности пищи - 72,4 [56,2; 98,8] г / сутки, в группе сравнения - 10\% от суточной калорийности пищи - 25,2 [11,0; 49,1] г / в сутки $(\mathrm{p}<0,05)$. Содержание транс-ненасыщенных жирных кислот в суточном рационе составило $2 \%$ общей суточной калорийности пищи у пациентов основной группы и 1,5\% общей суточной калорийности пищи у пациентов АГ с НМТ.

В работе был проведен корреляционный анализ между антропометрическими показателями больных и различными показателями характера питания. В результате анализа выявлены достоверные корреляционные взаимосвязи между показателем ИМТ и рядом показателей, характеризующих энергетическую ценность и макронутриентый состав пищи у обследованных больных АГ с сопутствующим АО. Так, ИМТ достоверно прямо коррелировал с показателем калорийности суточного рациона $(\mathrm{R}=0,46 ; \mathrm{p}<0,05)$, потреблением жиров $(\mathrm{R}=0,34$; $\mathrm{p}<0,01)$ и простых углеводов $(\mathrm{R}=0,42 ; \mathrm{p}<0,01)$.

Таким образом, у больных АГ с АО установлена большая энергетическая ценность суточного рациона на фоне более выраженных нарушений режима питания, что ассоциировалось со значительным 
дисбалансом макронутриентного состава суточного рациона: пониженным потреблением пищевых волокон и повышенным потреблением насыщенных жирных и транс-ненасыщенных жирных кислот.

Выводы.

1. Характер питания больных АГ с АО достоверно отличался от такового у больных АГ с НМТ более высокой энергетической ценностью суточного рациона (достоверно большим потреблением жиров и углеводов, на фоне отсутствия разницы в потреблении белков).

2. Установлено несоответствие суточного рациона питания нормам здорового питания, что заключалось в недостаточном потреблении пищевых волокон и превышении допустимых норм потребления насыщенных жирных кислот и транс-ненасыщенных жирных кислот.

3. ИМТ как показатель, характеризующий степень ожирения, достоверно прямо коррелировал с общей калорийностью суточного рациона, количеством потребленных жиров и простых углеводов.

\section{Литература:}

1. Коваль С.М., Старченко Т.Г., Юшко К.О., Мисниченко О.В., Пенькова М.Ю., Гальчинська В.Ю., Корнійчук І.А., Щенявська О.М., Літвінова О.М. Динаміка ремоделювання лівого шлуночка у хворих на артеріальну гіпертензію в поєднанні з цукровим діабетом 2-го типу та ожирінням під впливом однорічної комбінованої терапії. Артериальная гипертензия. 2019. № 3-4 (65-66), С. 53-59.

2. Фадєєнко Г.Д., Ісаєва Г.С., Рєзнік Л.А. Роль харчових волокон у профілактиці серцево-судинних захворювань. Серце та судини. 2016. № 4, C. 104-109.

3. Diet, Physical Activity and Cardiovascular Disease Prevention in Europe. European Heart Network. 2011. 192 p.

4. Piepoli M.F., Hoes A.W., Agewall S. et al. European guidelines on cardio-vascular disease prevention in clinical practice. European Heart Journal. 2016. Vol. 37, P. 2315-2381.

5. Рекомендації Української Ассоіції кардіологів з профілактики та лікування артеріально гіпертензії . 4-е вид., випр. I доп. Київ. ППВМБ, 2013. $80 \mathrm{c}$.

6. $2018 \mathrm{ESC} / \mathrm{ESH}$ Guidelines for the management of arterial hypertension. European Heart Journal. 2018. V. 39, P. 3021-3104.

7. WHO: Global Action Plan for the Prevention and Control of NCDs 2013-2020. URL: https://www.who.int/nmh/events/ncd_action_plan/en/

8. Наказ № 1073 МО3 України від 03.09.2017 р. Норми фізіологічних потреб населення України в основних харчових речовинах $\mathrm{i}$ енергії. 02 жовтня 2017 р. за № 1206/31074 